\title{
Goal-directed and habitual control in the basal ganglia: implications for Parkinson's disease
}

\author{
Peter Redgrave*, Manuel Rodriguez ${ }^{\ddagger}, \S$, Yoland Smith\|, $\|$, Maria C. Rodriguez-Oroz ${ }^{\S}, \#$, \\ Stephane Lehericy $^{\star \star}$, Hagai Bergman ${ }^{\ddagger \ddagger}$, Yves Agid§§, Mahlon R. DeLong ${ }^{\mathbb{I}}$, and Jose A. \\ Obeso§,\# \\ "Neuroscience Research Unit, Department of Psychology, University of Sheffield, S10 2TP, UK. \\ ‡Department of Physiology, Medical School, University of La Laguna, Tenerife, 38201, Spain. \\ §Centro de Investigación Biomédica en Red sobre Enfermedades Neurodegenerativas \\ (CIBERNED), Instituto Carlos III, Ministerio de Investigacion y Ciencias, 28038, Spain. \\ "Yerkes National Primate Research Center, Emory University, Atlanta, Georgia 30329, USA. \\ IDepartment of Neurology, Emory University School of Medicine, Atlanta, Georgia 30322, USA. \\ \#Movement Disorders Group, Neurosciences Division, CIMA and Department of Neurology and \\ Neurosurgery, Clínica Universidad de Navarra, Pamplona, 31008, Spain. \\ ${ }^{* *}$ Centre de Neurolmagerie de Recherche (CENIR), Institut du Cerveau et de la Moelle épinière \\ (ICM), Universite Pierre et Marie Curie, Inserm U975, CNRS 7225, Groupe Hospitalier Pitié- \\ Salpêtrière, 75013, Paris, France. \\ ‡¥Hebrew University, Hadassah Medical School, Jerusalem 91120, Israel. \\ $\S \S$ Institut du Cerveau et de la Moelle épinière (ICM), 75013, Paris, France.
}

\begin{abstract}
Progressive loss of the ascending dopaminergic projection in the basal ganglia is a fundamental pathological feature of Parkinson's disease. Studies in animals and humans have identified spatially segregated functional territories in the basal ganglia for the control of goal-directed and habitual actions. In patients with Parkinson's disease the loss of dopamine is predominantly in the posterior putamen, a region of the basal ganglia associated with the control of habitual behaviour. These patients may therefore be forced into a progressive reliance on the goal-directed mode of action control that is mediated by comparatively preserved processing in the rostromedial striatum. Thus, many of their behavioural difficulties may reflect a loss of normal automatic control owing to distorting output signals from habitual control circuits, which impede the expression of goaldirected action.
\end{abstract}

The basal ganglia are a group of subcortical nuclei that have been linked to movement control since the end of the nineteenth century when David Ferrier concluded that the corpus striatum contained "the centres of automatic or sub-voluntary integration"(REF. ${ }^{1}$ ). This

\footnotetext{
(C) 2010 Macmillan Publishers Limited. All rights reserved

Correspondence to P.R. and J.O. P.Redgrave@ sheffield.ac.uk; jobeso@ unav.es.

Competing interests statement The authors declare no competing financial interests.

FURTHER INFORMATION Peter Redgrave's homepage: http://www.shef.ac.uk/psychology/staff/academic/peter-redgrave.html Jose A. Obeso's homepage: http://www.cima.es/areas/neurociencias

ALL LINKS ARE ACTIVE IN THE ONLINE PDF
} 
view was expanded in the early twentieth century by observations that basal ganglia lesions were associated with movement disorders (BOX 1). The first functional model of basal ganglia architecture was developed in the late 1980s (FIG. 1a). In this model, cortical inputs enter the basal ganglia through the striatum (in primates this consists of the caudate nucleus and the putamen), and the internal globus pallidus (GPi) and the substantia nigra pars reticulata $(\mathrm{SNr})$ serve as the principal output nuclei. The activity of striatal medium spiny projection neurons is conveyed to the output nuclei ( $\mathrm{GPi}$ and $\mathrm{SNr}$ ) through a monosynaptic GABA ( $\gamma$-aminobutyric acid)-ergic projection (the 'direct' pathway) and a polysynaptic ('indirect') pathway that involves relays in the external globus pallidus (GPe) and the subthalamic nucleus $(\mathrm{STN})^{2}{ }^{3}$. Output from GABAergic GPi and $\mathrm{SNr}$ neurons keep targeted structures in the thalamus and brainstem under tonic inhibitory control: this tonic inhibition is blocked (that is, paused) by phasic inhibitory signals from the 'direct' striato-nigralpallidal projection ${ }^{4}$, which releases thalamocortical and brainstem structures from inhibition, thereby allowing movement to proceed. Dopaminergic input from the substantia nigra pars compacta (SNc) modulates corticostriatal transmission by exerting a dual effect on striatal projection neurons (FIG. 1). Neurons that co-express dopamine D1 receptors, substance P and dynorphin and give rise to the 'direct pathway' are excited by dopamine, whereas neurons that co-express D2 receptors and encephalin, and that give rise to the 'indirect pathway', are inhibited ${ }^{5}$ (FIG. 1a). Consequently, according to this model, in the normal state, activation of the 'indirect circuits' at the level of the striatum would promote movement inhibition or arrest, whereas activation of the 'direct circuit' would facilitate movement ${ }^{3},{ }^{6}$.

In the parkinsonian state, reduced dopamine input from the SNc to the striatum would have a dual effect, facilitating neurons that give rise to the 'indirect' projection and reducing the activation of 'direct pathway' neurons ${ }^{7}$. Increased inhibition from 'indirect' striatal neurons to the GPe disinhibits the STN, which then overdrives inhibitory output neurons in the GPi and $\mathrm{SNr}^{6},{ }^{8}$. In parallel, decreased activation of 'direct pathway' striatal output neurons would effectively reduce the phasic inhibitory influences on the GPi and $\mathrm{SNr}$, thereby contributing to excessive activation of inhibitory basal ganglia output. The dyskinetic state is thought to result from an opposite set of changes (inhibition instead of excitation) ${ }^{8}$. Here, reduced STN activity and corresponding reductions in basal ganglia inhibitory output would facilitate involuntary movements ${ }^{6,8,9}$.

\section{Box 1}

\section{Historical hallmarks of basal ganglia function and pathophysiological models (1912-1990)}

- Wilson's disease and striatal dysfunction (1912-1925). The main clinical manifestation of a bilateral striatal lesion secondary to copper deposition was movement impairment ${ }^{160}$. Later, the striatum was associated with the control of muscle tone ${ }^{161}$. These early findings established the link between the basal ganglia and movement disorders.

- Lesions of the subthalamic nucleus (STN) associated with hemiballismus (1927 and 1934). Patients who suffered a sudden onset of violent and ceaseless movements of the contralateral hemibody were shown to have a haemorrhage that destroyed the subthalamic nucleus ${ }^{162},{ }^{163}$. Consequently, the STN was originally thought to inhibit movement ${ }^{164}$. However, it is now recognized that the subthalamus provides excitatory input to the tonically active inhibitory output architecture of the basal ganglia.

- Lesions of the globus pallidus pars interna (GPi) or the ventrolateral thalamus block hemiballismus (1948 and 1959). Pallidotomy was shown to abolish the 
dyskinesia in monkeys with hemiballismus induced by unilateral lesion of the $\mathrm{STN}^{165},{ }^{166}$. In a patient with hemiballismus that did not abate spontaneously, a thalamotomy subsequently abolished the dyskinesias ${ }^{166}$. These findings represent early examples of how lesions of basal ganglia circuitry can both induce and ameliorate movement disorders.

- Recognition of the importance of globus pallidus output (1962). Experiments in monkeys and clinical studies indicated that the GPi is the 'head ganglion' of the motor system ${ }^{164}$. Together with the substantia nigra pars reticulata and the GPi, the basal ganglia output nuclei exert powerful inhibitory control over multiple levels of the neuraxis.

- Striatal dopamine depletion associated with Parkinson's disease and the effect of levodopa (1960). A profound reduction ( $>80 \%$ below control values) in dopamine striatal concentration was detected in patients with Parkinson's disease and in patients with postencephalitic parkinsonism ${ }^{167}$. This was followed by investigations into the effect of levodopa in patients with Parkinson's disease ${ }^{168}$. After some initial doubts, levodopa was confirmed as being an effective treatment when used in the correct dose ${ }^{169}$ (see REF. ${ }^{170}$ for a review). Tonic activity in ascending dopamine systems was finally acknowledged as being essential for normal function within the basal ganglia.

- Proposal of the 'selection' function of the basal ganglia (1976 and 1978). The basal ganglia have all the aspects of a 'clearing house' that receives samples of ongoing cortical activity and facilitates (selects) one while suppressing all others $^{171}$. Hassler wrote "The basal ganglia at the same time focus the attention, emotional participation and excitability on one single event by simultaneously suppressing and fading all other happenings and motivational objects" (REF. 172 ). From this point onwards a recurring theme in basal ganglia literature has been 'selection' that is implemented by selective disinhibition ${ }^{4}$ within the looped architectures that connect the basal ganglia with the cerebral cortex and brainstem structures 49 .

- Importance of the basal ganglia for the expression of automatic movements (1982). Sequential or simultaneous motor tasks are characteristically impaired by the loss of dopamine in early stages of Parkinson's disease. The basal ganglia are responsible for the "automatic execution of learned motor plans" (REF. 111). This idea has developed into the recognition that parts of the basal ganglia play a crucial part in the expression of habits $64,66,157$.

Although this original model has provided a useful heuristic and spawned many valuable experimental studies and clinical developments, it is increasingly perceived as having important limitations. Over the past quarter century, many new anatomical, functional and clinical data have become available and they provide a rather different appreciation of basal ganglia architecture and function. In this review, we present a contemporary summary of the structural organization of the basal ganglia and a developing systems-level analysis of their general functional organization. Specifically, we review a body of recent data showing that regionally segregated functional territories of the basal ganglia contribute to networks that regulate goal-directed and habitual behaviours. Based on this information, we propose that the well-established preferential loss of dopamine in the sensorimotor territories of many patients with Parkinson's disease may cause a major deficit in habitual control, and that pathological output from dysfunctional sensorimotor circuitry will distort the expression of residual goal-directed responses. 


\section{Structural organization of the basal ganglia}

Since the 'direct versus indirect pathway' model of basal ganglia function was introduced, there have been important anatomical discoveries that were not anticipated by the model's original proposers $2,3,6,{ }^{3}$. Here we present a brief and necessarily selective review of relevant anatomical findings that describe intrinsic connections between the basal ganglia nuclei and the pathways that connect the basal ganglia to other brain regions. These structural details place important constraints on the computational processing that the basal ganglia can be expected to perform.

\section{Intrinsic connections}

Although the 'direct' and 'indirect' pathways proposed in the original model remain valid (FIG. 1a), it is now recognized that they represent a subset of the connections between the basal ganglia nuclei, albeit an important one (FIG. $1 b^{10}$ ). First, an additional feature of the 'direct' pathway from the striatum to the output nuclei is the branching collateral fibres that terminate sparsely in GPe ${ }^{11},{ }^{12}$ (FIG. 1b). Second, the exclusive feedforward nature of the 'indirect projection' from the striatum is no longer tenable. The STN is now recognized as a major input station of the basal ganglia with external afferents from both cortical and subcortical structures ${ }^{13}{ }^{18}$ (FIG. 1b). The GPe projects not only to the STN but also directly to the GPi and $\mathrm{SNr}$, and to nigrostriatal dopamine neurons, often via a network of branched collaterals ${ }^{19}$. Although the feedforward nature of information processing in the basal ganglia is still prominent, clear examples of reciprocal connectivity between basal ganglia nuclei are now evident between the STN and GPe ${ }^{19}{ }^{21}$, and between the GPe and the striatum ${ }^{20}{ }^{22}{ }^{24}$ (FIG. 1b).

A widely recognized feature of connections between the intrinsic nuclei of the basal ganglia is their high degree of spatial topography ${ }^{25}{ }^{27}$. Thus, in primates, projections from the striatum to the globus pallidus and substantia nigra maintain a general arrangement throughout the different intrinsic nuclei, whereby the posterior putamen is engaged in sensorimotor functions, the caudate and anterior putamen in associative functions, and the ventral (limbic) striatum in motivational and emotional functions ${ }^{28}$ (FIG. 2). Accordingly, the direct projections between the striatum and the basal ganglia output nuclei represent the internal component of the general, partially segregated, looped architecture that connects the basal ganglia with extrinsic cortical ${ }^{29}$ and subcortical structures ${ }^{30}$. A further feature with functional importance is that, although they are individually different, the internal microcircuits in each of the basal ganglia nuclei are, with certain quantitative differences, qualitatively similar (in terms of cell types and local connections) across the different functional zones of each structure (limbic, associative and sensorimotor) ${ }^{31}{ }^{36}$. Thus, insofar as function is an emergent property of connectivity, it is likely that throughout the different basal ganglia nuclei, similar input-output computations are being applied to widely differing functional signals (affective, cognitive and sensorimotor signals).

\section{Extrinsic connections}

We now consider the main connections between the basal ganglia and external structures, namely the parallel-projecting, partially segregated reentrant loops ${ }^{27},{ }^{29},{ }^{30}$. Most of the functionally segregated regions of the cerebral cortex provide topographically organized input to the principal input nuclei of the basal ganglia ${ }^{14}, 25,29,35$. Cortical regions associated with limbic (that is, emotional), associative (that is, cognitive) and sensorimotor functions provide topographically ordered input extending from ventromedial to dorsolateral zones of the striatum - limbic input projects to ventromedial zones, sensorimotor input to dorsolateral zones and associative input to the region in between ventromedial and dorsolateral zones (FIG. 2). These projections are the first link in the parallel loop 
component of corticobasal ganglia architecture ${ }^{27},{ }^{29}$. This looped architecture has been shown in anatomical studies of a range of species ${ }^{25}{ }^{27}$, including humans ${ }^{37}{ }^{39}$.

The re-entrant loops described above were not the first evolutionary example of closed-loop architecture involving the basal ganglia and external structures ${ }^{30}$. Indeed, there is a phylogenetically older set of closed-loop subcortical connections between the basal ganglia and brainstem sensorimotor structures, which include the superior and inferior colliculi ${ }^{40},{ }^{41}$, periaqueductal grey ${ }^{42}$, pedunculopontine nucleus ${ }^{43}$, cuneiform area and parabrachial complex ${ }^{40}$, and various pontine and medullary reticular nuclei ${ }^{40}$.

Finally, the ascending dopaminergic system provides important modulatory influences on basal ganglia processing. The projection from the $\mathrm{SNc}$ and the ventral tegmental area targets all intrinsic nuclei of the basal ganglia but with preferential concentrations of terminals in the dorsal and ventral striatum ${ }^{44}$ (FIG. 1b). The main nigrostriatal projection maintains a general medial to lateral topography ${ }^{45}$. There is also a sparser dopamin ergic innervation of both the globus pallidus ${ }^{46}$ and STN ${ }^{47}$. The ascending dopaminergic systems have both tonic and phasic patterns of activity ${ }^{48}$. Tonic firing is essential for normal 'selective functions' of the basal ganglia ${ }^{49}{ }^{51}$, whereas sensory-evoked phasic activity provides 'teaching signals' for instrumental learning ${ }^{52}{ }^{54}$.

To summarize, layers of complexity at all levels have been added beyond those envisaged in the original 'direct versus indirect pathway' model (FIG. 1b). It is now recognized that the basal ganglia are subdivided anatomically into functional domains that have topographically organized connections with external structures that contribute to emotional, associative and sensorimotor functions.

\section{Functional divisions of the basal ganglia}

Micro-stimulation and micro-recording investigations in behaving monkeys ${ }^{55}{ }^{60}$, and functional imaging studies in humans ${ }^{26},{ }^{61},{ }^{62}$ have shown that signals from subregions of the basal ganglia nuclei accord well with the functional status of their inputs. Thus, the consequent tripartite division of the basal ganglia into limbic (motivational and emotional), associative (cognitive) and sensorimotor networks has provided a functional framework onto which different forms of associative learning ${ }^{63}$ have been successfully mapped ${ }^{64}{ }^{66}$. However, to provide an appreciation of the neural systems responsible for instrumental learning in the form of goal-directed action-outcome control and the acquisition of habits, we will restrict ourselves to a consideration of the respective roles of the associative and sensorimotor territories in the basal ganglia.

\section{Dual systems for instrumental control}

Early analyses of instrumental behaviour stressed the importance of reinforced associations between stimuli and responses ${ }^{67},{ }^{68}$. However, during the past 20 years it has become clear that animals can also encode causal relationships between actions and outcomes ${ }^{63},{ }^{64},{ }^{69}$. Consequently, when behaviour is goal-directed, action selection is determined primarily by the relative utility of predicted outcomes, that is, the value of the possible outcomes of different actions. To discover whether a particular action is goal-directed or under stimulus control (that is, habitual or automatic), a series of formal behavioural tests have been developed.

The first involves changing outcome desirability ${ }^{70}$. Here, an animal learns that an action (for example, pressing a lever) triggers the delivery of a particular type of food. However, if the animal is allowed to satiate itself with that food before the test, the utility of the food would be devalued. Thus, if during subsequent testing the animal makes fewer actions to obtain the 
(now) devalued outcome, its behaviour is considered to be goal-directed. Alternatively, if the animal maintains its behaviour (that is, presses the lever) despite the devalued outcome, the behaviour is considered to be under stimulus control (that is, habitual) ${ }^{63}{ }^{66}, 69$. A second test involves degrading the contingency relationship between action and outcome ${ }^{71}$. For example, the experimenter can ensure that food delivery sometimes occurs without the animal performing the required action (for example, pressing a lever). Under these conditions decreased responding would reflect goal-directed control of behaviour, whereas maintained responding would reflect habitual control of behaviour ${ }^{72}$.

These tests have been used to show that different functional territories within the basal ganglia - and the structures to which they are connected through the looped architecture are responsible for goal-directed and habitual control of behaviour, respectively, in both animals and humans ${ }^{65},{ }^{73}$. However, we will first consider how dual control systems can operate in tandem.

\section{Goal-directed or habit?}

What happens when an Englishman drives a car in Spain or a Spaniard drives a car in England? Goal-directed systems will work hard to keep the car on the right and left side of the road, respectively. However, it only takes a moment's inattention or distraction, or an emergency, for stimulus-response habit systems to gain control, with distressing consequences. Given that a behaviour (in this case, driving) can be regulated either by goaldirected or habitual control systems, what processes or mechanisms determine whether the dual controllers act cooperatively or in competition?

Experimentally, several factors have been shown to determine whether the agent (animal or human) operates in goal-directed or habitual mode. The first is over-training: here, initial control is largely goal-directed, but with consistent and repeated training there is a gradual shift to stimulus-response, habitual control ${ }^{70}$. Once habits are established, habitual responding tends to dominate, especially in stressful situations in which quick reactions are required ${ }^{74}$. The second related factor is task predictability: in the example of driving ${ }^{64}$, talking on a mobile phone is fine so long as everything proceeds predictably. However, if something unexpected occurs, such as someone stepping out into the road, there is an immediate switch from habitual to goal-directed control ${ }^{75}$. Making this switch takes time and this is one of the reasons why several countries have banned the use of mobile phones while driving ${ }^{76}$. The third factor is the type of reinforcement schedule: here, fixed-ratio schedules promote goal-directed control as the outcome is contingent on responding (for example, a food pellet is delivered after every $n$ responses). By contrast, interval schedules (for example, schedules in which the first response following a specified period is rewarded) facilitate habitual responding because contingencies between action and outcome are variable ${ }^{77}$. Finally, stress, often in the form of urgency, has a powerful influence over which mode of control is used. The fast, low computational requirements of stimulus-response processing ensure that habitual control predominates when circumstances demand rapid reactions (for example, pulling the wrong way in an emergency when driving on the opposite side of the road). Chronic stress also favours stimulus-response, habitual control $^{78},{ }^{79}$. For example, rats exposed to chronic stress become, in terms of their behavioural responses, insensitive to changes in outcome value and resistant to changes in action-outcome contingency ${ }^{79}$.

\section{Goal-directed and habitual control in concert}

Although these factors can be seen as promoting one form of instrumental control over the other, real-world tasks often have multiple components that must be performed simultaneously or in rapid sequences. Taking again the example of driving ${ }^{64}$, a driver is 
required to continue steering while changing gear or braking. During the first few driving lessons, when steering is not yet under automatic stimulus-response control, things can go horribly awry when the new driver attempts to change gears. By contrast, an experienced (that is, 'over-trained') driver can steer, brake and change gear automatically, while holding a conversation, with only fleeting contributions from the goal-directed control system. This suggests that many skills can be deconstructed into sequenced combinations of both goaldirected and habitual control working in concert ${ }^{75},{ }^{80}$. Formal demonstrations of this have been reported by Balleine and Ostlund ${ }^{81}$.

Nevertheless, a fundamental problem remains: at any point in time, which mode should be allowed to control which component of a task? Daw et al. ${ }^{82}$ have used a computational approach to address this problem. Their analysis was based on the recognition that goaldirected responding is flexible but slow and carries comparatively high computational costs as opposed to the fast but inflexible habitual mode ${ }^{83}$. They proposed a model in which the relative uncertainty of predictions made by each control system is tracked. In any situation, the control system with the most accurate predictions comes to direct behavioural output. It is likely that the looped architecture that connects relevant functional territories of the cerebral cortex with the basal ganglia plays a crucial role in switching between habitual and goal-directed modes of action control ${ }^{75}$.

\section{Goal-directed and habitual control in the basal ganglia}

In a seminal series of studies Yin et al. ${ }^{66}, 84 \_87$ showed that inactivation of the dorsomedial (associative) region of the rodent striatum, either with neurotoxins or local injections of the GABA agonist muscimol, blocked goal-directed control, as revealed by a reduced sensitivity (in terms of behaviour) to outcome devaluation and a degradation of action-outcome contingency 85,86 (FIG. 3a). In experiments in which habitual responding was induced by over-training, control animals were insensitive to outcome devaluation ${ }^{84}$ and contingency degradation ${ }^{87}$ (that is, they showed habitual responding), whereas animals with dorsolateral (sensorimotor) striatal lesions returned to goal-directed control and adjusted their behaviour accordingly. These results show that the dorsomedial and the dorsolateral striatum regulate goal-directed and stimulus-response habitual control, respectively.

Miyachi and colleagues provided evidence for a homologous functional organization within the nonhuman primate basal ganglia — in which the caudate nucleus and rostral putamen correspond to the rodent dorsomedial striatum, and the posterior putamen to the rodent dorsolateral territories - in two important experiments. In the first ${ }^{88}$, local inactivation of associative territories of the monkey striatum impaired the acquisition of novel motor sequences but left the performance of well-learned sequences comparatively unaffected. Conversely, inactivation of the middle-to-caudal, sensorimotor part of the putamen disrupted the execution of well-learned sequences, but animals were still able to acquire new sequences. In the second experiment ${ }^{89}$, neurons in the associative part of the striatum were preferentially activated when monkeys were learning new motor sequences, whereas neurons in the sensorimotor territories were active when the animals performed welllearned, automatic sequences of movements. The concept of homologies across species was extended further in a recent review by Balleine and O'Doherty ${ }^{65}$, in which parallels were drawn between the functional organization of the striatum in rodents and that in humans. In humans, blood oxygen level-dependent (BOLD) activation of the caudate nucleus and the regions of the prefrontal cortex associated with it occurs during goal-directed behaviours, such as set shifting 90 , action planning ${ }^{91}$ and cognitive manipulations ${ }^{92}$. During prolonged training on motor tasks (when performance would be expected to shift from being under goal-directed to being under habitual control), the activation pattern gradually shifts from rostromedial (associative) to caudolateral (sensorimotor) regions of the striatum $93,{ }^{94}$. Studies using formal tests of goal-directed and habitual control have provided confirmation 
that behavioural control systems are localized in different regions of the human striatum. For example, Tanaka et al. ${ }^{95}$ reported increased activation of the anterior caudate nucleus in subjects performing on a high (goal-directed) action-outcome contingency schedule compared with subjects performing a low action-outcome contingency schedule that promotes habitual responding (FIG. 3b). By contrast, the caudal putamen was preferentially activated during an outcome devaluation test when subjects' behavioural responses were habitual $^{96}$ (FIG. 3c). Thus, in rodent, monkey and human striatum, goal-directed and habitual control is mediated independently by circuits that connect with the associative and sensorimotor functional territories of the striatum, respectively ${ }^{65}$. In view of the relative differences in the location of these territories in the rodent and primate striatum, from this point we will use the general terms 'rostromedial' (associative) and 'caudolateral' (sensorimotor) when referring to striatal functional territories in either species.

\section{The need for selection}

The structural evidence reviewed above established that the parallel looped architecture is common to all functional territories of the basal ganglia. In addition, components of intrinsic micro-circuits are qualitatively, if not quantitatively, similar across the functional zones of basal ganglia nuclei. It therefore seems likely that the basal ganglia perform the same (or similar) general computational function in goal-directed and stimulus-response habitual control systems. A prominent view, which comes in several forms ${ }^{49}{ }^{51}, 53,66$, holds that basal ganglia architecture seems to be ideally configured to perform a generic 'selection' function ${ }^{49}$. Indeed, the parallel loop architecture ${ }^{29}, 3^{3}$ - combined with selective disinhibition at the level of the output nuclei ${ }^{4}$ - results in effective action selection, in computational models ${ }^{97}{ }^{99}$ and in behavioural control of a mobile robot ${ }^{100}$.

Presumably, it is the capacity of the basal ganglia to select between competing options that defines their role in goal-directed and habitual control of behaviour. Thus, if in any situation brain regions with access to associative territories of the basal ganglia are likely to generate diverse, often mutually exclusive behavioural options ${ }^{101}$ (that is, a range of potentially incompatible outcomes and their associated causal actions), a mechanism would be required to select a 'winner that takes all'. Similarly, afferent structures that provide input to sensorimotor regions of the basal ganglia may also simultaneously represent multiple habitevoking stimuli. In this case, the question arises as to which stimulus-response pairing should be permitted to dominate. Therefore, the external structures that generate multiple cognitive (goal-directed) and stimulus-response (habit) options may need to interact with the basal ganglia to determine which option should be permitted to guide behavioural output ${ }^{10,49}, 53$.

\section{The final common motor path}

It was noted above, first, that the same act (for example, pressing a lever) can be performed under either goal-directed or habitual control ${ }^{80}$. Second, findings from inactivation and lesion studies have shown that goal-directed and stimulus-response habitual control are mediated independently by neural circuits that course through different regions of the striatum ${ }^{66},{ }^{84} \_88,95,96$. Thus, if the same act, set of movements or action sequence can be performed independently by spatially separated functional systems (at the level of the basal ganglia), the implication is that the output of goal-directed and habitual control systems must at some point converge on lower level motor structures that generate behavioural output. Where the proposed convergence takes place is unknown, and there are many possible areas where the 'final common motor path' might become 'common'. An early location where associative and sensorimotor outputs from the basal ganglia could converge is on the motor output neurons in the cortical ${ }^{29}$ or brainstem sensorimotor regions ${ }^{30}$ that connect to the basal ganglia via the sensorimotor loops. These motor neurons may be driven 
by direct sensory inputs (for stimulus-response habitual responding) ${ }^{102}$ and also by inputs from higher-level structures that are involved in goal-directed control ${ }^{103}{ }^{105}$. The last place where the proposed convergence could take place is through multi-synaptic relays terminating on common motor neurons in the brainstem and spinal cord ${ }^{106}$. In any case, it is necessary to assume that spatially segregated goal-directed and habitual control systems (at the level of the basal ganglia) at some point converge on motor output mechanisms, and that this inferred convergence will have important implications for the interpretation of the functional deficits in patients with Parkinson's disease.

\section{A model of basal ganglia dysfunction}

When the classic motor features of Parkinson's disease appear, dopaminergic neurons in ventrolateral substantia nigra and their terminals in the caudolateral sensorimotor putamen are differentially susceptible to degeneration ${ }^{107}$. Indeed, positron emission tomography (PET) imaging typically reveals reduced levels of ${ }^{18}$ fluorodopa uptake mainly in caudal regions of the striatum ${ }^{108}$ (FIG. 4). This is consistent with post-mortem data showing the greatest loss of dopaminergic innervation to be from the posterior putamen ${ }^{109}$ and a corresponding loss of dopaminergic cells in the ventrolateral $\mathrm{SNc}^{110}$. Thus, dysfunction of basal ganglia sensorimotor circuits marks the initial stages of Parkinson's disease ${ }^{111}, 112$. Given that these are the regions through which stimulus-response habitual control is exercised, a principal feature of the disease should be an impaired ability to acquire and express (in other words, to select) habitual actions (FIG. 5). Indeed, it has long been known that patients with Parkinson's disease have difficulties expressing automatic components of behaviour ${ }^{113},{ }^{114}$ and are impaired in their implicit learning of habits ${ }^{115}$. If the territories of the basal ganglia that underlie habitual control malfunction in these patients (FIG. 5), then these patients would have to perform most, if not all, aspects of tasks - from the mundane to the complex - in a volitional and goal-directed manner ${ }^{116}$. Direct evidence supporting this point is, however, scarce at present and will depend on the continuing translation of the formal behavioural tests from animal learning theory $65,{ }^{70},{ }^{71}$ into the human arena, in a form that is suitable for testing in patients with Parkinson's disease.

\section{Trapped in goal-directed control}

A brief survey of the observed differences between the goal-directed and automatic (stimulus-response habit) modes of behavioural control will provide insights into what a preferential loss of the automatic stimulus-response system in patients with Parkinson's disease might entail. First, extended and consistent training is required to develop automatic processing ${ }^{83}$. Consequently, patients with Parkinson's disease would be expected to have great difficulty developing habitual responding despite repeated practice ${ }^{115}, 117,118$. This has also been demonstrated in a rodent 6-hydroxydopamine lesion model of Parkinson's disease. Here, selective loss of dopamine from the lateral SNc and lateral striatum caused behaviour to remain goal-directed, despite over-training, whereas control animals showed normal habit development ${ }^{119}$. Second, automatic processing is fast and parallel, whereas controlled processing is slow and serial ${ }^{83}$. With a progressive loss of rapid, low-cost habitual processing, we would predict that patients with Parkinson's disease would have to rely increasingly on the slower, serial goal-directed control system. Third, automatic control requires little cognitive effort and can operate in multitasking situations involving high workload $^{83}$. Thus, a gradual replacement of automatic control by effortful, goal-directed processing in patients with Parkinson's disease should render their task in hand increasingly subject to interference from other goal-directed tasks ${ }^{113},{ }^{120},{ }^{121}$. Indeed, these patients require a conscious decision to start walking and they stop abruptly if they are distracted by a different external stimulus, a new idea or another behaviour (for example, talking) ${ }^{116},{ }^{122}$. Fourth, once action sequences have become automatic it is often difficult to revert to conscious volitional control ${ }^{83}$. Therefore, if our proposal that patients with Parkinson's 
disease increasingly have to operate in goal-directed control mode is correct, this could explain why they have particular problems with the automatic components of action sequences ${ }^{123}{ }^{125}$ and are generally slow during the execution of common daily life activities.

In addition to the increasing difficulties with the automatic, habitual components of behaviour, patients with Parkinson's disease often experience executive dysfunction, which can also appear early during the disease ${ }^{112}$. In most cases, however, it is unclear whether these deficits reflect a partial, disease-related loss of dopaminergic input to associative territories of the striatum ${ }^{126}$ or whether the loss of normal habits imposes a debilitating load on the serial operation of goal-directed control ${ }^{83},{ }^{116},{ }^{121}$.

\section{Impaired automatic (habitual) movements}

Because many actions have both goal-directed and habitual components ${ }^{80}$, malfunctioning of sensorimotor loops should preferentially block the habitual components from reaching expression. Accordingly, in patients with early stage Parkinson's disease, the ability to carry on performing normal automatic, habitual components of actions (for example, blinking, arm-swinging, facial expressions, pacing of gait, speech modulation and swallowing) is impaired $^{111}$, and this ability is further aggravated when patients are required to engage in goal-directed activities ${ }^{114}, 121$.

A possible objection to our proposal is that although automatic and well-learned movements and tasks are reduced in frequency, amplitude and speed in patients with Parkinson's disease, automatic functions are not completely eradicated ${ }^{125}$. One reason for this preservation of function could be that the degeneration of dopaminergic input to sensorimotor striatal areas is incomplete. At the time of diagnosis, dopamine depletion in the posterolateral putamen on the clinically affected side is usually about $60 \%{ }^{126}$. A second objection could be that patients with Parkinson's disease show an improvement in motor performance when they are guided by sensory stimuli ${ }^{116},{ }^{127},{ }^{128}$, which suggests that their sensorimotor control circuits may still be operational. However, sensory input is equally important for goal-directed control ${ }^{129}$ (FIG. 5). Thus, for patients with Parkinson's disease, the presence of a salient external stimulus to guide their movements could offer substantial advantage over movements initiated by internally generated 'cognitive' signals ${ }^{116},{ }^{121}$. Third, it is also noted that some automatic movements (for example, conditioning of the blink reflex) are preserved in patients with Parkinson's disease ${ }^{130}$. However, such movements commonly reflect the expression of classically conditioned reflexes associated more with cerebellar and limbic circuitry ${ }^{131},{ }^{132}$ than with instrumental action-outcome or stimulus-response learning mediated by the basal ganglia.

\section{Difficulty in initiating and executing movements}

The dual control model in FIG. 5 shows goal-directed and habitual control circuits converging on a final common motor path. Although, as observed above, the precise location (or locations) of this convergence remains to be determined, two possible sites are illustrated; one at the level of cortical sensorimotor output and the other in brainstem motor systems. Many experimental investigations have shown that basal ganglia output is abnormal in patients with Parkinson's disease and in animal models of the disease ${ }^{133},{ }^{134}$. Typically, neurons in the STN and GPi show increased firing ${ }^{135}, 136$ and abnormal patterns of synchronised oscillations ${ }^{137}{ }^{139}$. Therefore, in the Parkinsonian state, the downstream motor structures onto which both control systems presumably converge would be expected to receive one relatively normal set of signals (from the goal-directed system) and one set of pathological signals (from the stimulus-response habit system) (FIG. 5). Given that basal ganglia output is tonically active and inhibitory ${ }^{4}$, the distorting signals from dopamine- 
deprived stimulus-response habit circuits are likely to result in increased inhibition ${ }^{133},{ }^{134}$ and abnormal oscillations ${ }^{140}$. Thus, for the goal-directed system to operate effectively (that is, to generate appropriate behavioural output), it would have to overcome the inhibitory distortion from the malfunctioning stimulus-response habitual control circuits in the basal ganglia. It is therefore noteworthy that a recent imaging investigation ${ }^{117}$ reported increased activity but less effective connectivity in areas of the brain that are associated with the production of automatic movements in patients with Parkinson's disease. The patients also failed to show the normal reduction in dorsolateral prefrontal cortical connectivity as learning progressed from novel (that is, goal-directed) to automatic stages. These results are consistent with the notion that goal-directed control has to overcome 'abnormal inhibition' in order for what used to be 'automatic' movements to be expressed by patients with Parkinson's disease. This idea would also explain many features of bradykinesia, like reduced amplitude of agonist muscle recruitment of a ballistic movement and rapid decline of repetitive movements ${ }^{141},{ }^{142}$. Furthermore, if distorting oscillatory inhibitory output from the sensorimotor loops is imposed on downstream motor systems in the absence of substantial goal-directed input, perhaps this could account for the tremor observed in patients with Parkinson's disease at rest. This would be consistent with the observation that an attempt to mimic parkinsonian tremor by stimulating GPi in monkeys did not change motor cortex excitability or induce tremor, suggesting that parkinsonian tremor may develop in downstream motor circuits ${ }^{143}$. When patients attempt to exercise goal-directed control, initially, they may be able to direct sufficient excitatory input to motor systems to overcome distorting oscillatory activity from the habit circuits. However, this level of goal-directed input seems to be difficult to sustain and so performance fatigues rapidly. This could explain why tremor stops at the beginning of a voluntary movement, only to resume seconds later ${ }^{141}$.

We are aware that the present functionally-based framework does not account for the origin of the typical parkinsonian resting tremor or for the resistance to passive displacement of a joint. That said, both cardinal features could represent other distorting influences that are imposed on basic downstream motor control mechanisms by abnormal output from the sensorimotor basal ganglia ${ }^{112}$.

\section{Why surgical lesions can be beneficial}

In the last 6 decades, many patients with Parkinson's disease and other movement disorders (perhaps some 100,000) have been treated by stereotactically defined lesions directed to different parts of the basal ganglia. The general observation is that regardless of how beneficial the procedure is, the patients' underlying motor problems are not aggravated and new motor difficulties are not induced ${ }^{142}$ when lesions are unilateral. The apparent impunity with which the basal ganglia can be lesioned to treat movement disorders without catastrophic effects on behaviour is a well recognized paradox ${ }^{144}$. The current framework permits an earlier idea ${ }^{142}$ that "it's better to have no basal ganglia output than a 'noisy' one" to be refined. We can now say that it may be better to have no output from stimulusresponse habitual control circuits than a 'noisy' one. The proposal of dual mechanisms for control of instrumental behaviour predicts that any treatment that stops or reduces distorting inhibitory signals coming from malfunctioning stimulus-response habitual control circuits that originate in the sensorimotor basal ganglia, should make goal-directed control easier. Presumably, therefore, surgical treatments work by blocking distorting efferent signals that make it difficult for the goal-directed system to operate efficiently (FIG. 5). In this context, it is worth pointing out that the most beneficial therapeutic results are achieved when inactivating treatments are directed to the sensorimotor - as opposed to the limbic or associative - territories of relevant basal ganglia nuclei ${ }^{145}$. 


\section{A double dissociation}

Our review of the neural substrates of goal-directed and stimulus-response habitual responding in animals highlights a double dissociation in which inactivating rostromedial striatal loops impair goal-directed — but not stimulus-response habitual - control ${ }^{85},{ }^{86}$, whereas inactivation of caudolateral striatal loops blocks habitual - but not goal-directed - responding ${ }^{84}{ }^{87}$. A similar double dissociation seems to emerge from comparing patients with Parkinson's disease with those suffering from cognitive abulia ${ }^{146}{ }_{147}$. Patients with abulia exhibit apathy, loss of motivation, a reduction in spontaneous behaviour and extreme poverty of thought, yet can perform a wide range of tasks if they are instructed to do so. For behaviour to continue it must be maintained by external sensory stimulation. Abulia seems to be caused by focal lesions to medial sectors of the basal ganglia, which may include both associative and mesolimbic territories. A favoured interpretation is that abulia represents a catastrophic loss of internally motivated goal-directed behaviour with relative preservation of direct stimulus-response control ${ }^{146},{ }^{147}$. If this is the case, patients with abulia show a double dissociation with patients in the early stages of Parkinson's disease, who seem to retain goal-directed abilities but have a relative loss of stimulus-response habitual control. It is, however, important to recognize that with increasing and progressive involvement of more medial sectors of the basal ganglia some of the motivational and cognitive symptoms of abulia — in particular, apathy — also become evident in Parkinson's disease ${ }^{148}$.

\section{Affective assistance}

Although we have concentrated on goal-directed and habitual control by the basal ganglia, to ignore influences of the mesolimbic territories on the behaviour of patients with Parkinson's disease would be a mistake (see REF. ${ }^{149}$ for a recent review). Insofar as the ventromedial dopaminergic systems seem to be comparatively spared ${ }^{107}{ }^{112}$ in Parkinson's disease, we would predict a commensurate sparing of motivational and emotional function in patients with Parkinson's disease. Thus, the relatively preserved motivation- and emotionbased selections made within intrinsic microcircuits of the limbic territories of the basal ganglia should still be able to guide and energize ${ }^{150}$ similarly spared goal-directed responding. The notion that powerful affective stimuli assist in goal-directed behavioural control can be seen in the oft-quoted example of patients with Parkinson's disease responding appropriately to a fire alarm or other emergencies. Similarly, classical Pavlovian associations and their ability to influence instrumental responding would be expected to be comparatively preserved in these patients, especially at the beginning of early-onset Parkinson's disease - this is because these associations are crucially dependent on neural processing in limbic structures ${ }^{131},{ }^{132}$ and their connections with striatal territories that are innervated by the mesolimbic dopamine system, which is comparatively preserved during the initial stages of Parkinson's disease.

\section{Conclusions and perspectives}

The conceptual level of the anatomical framework proposed in this article, and its implications for the mechanisms underlying the symptoms of Parkinson's disease, are different to those proposed by the original 'direct versus indirect pathway' model ${ }^{2}, 3$. In the original model the opposition was between anatomical pathways (the 'direct' and 'indirect' circuits facilitating and suppressing movement, respectively) (FIG. 1a). In the current framework, the opposition is based on dual, goal-directed and stimulus-response habitual control systems operating through regionally segregated functional territories of the basal ganglia (FIGS 3,5). Because the current proposal is at a different functional level of description, it makes no prescriptions concerning the relative contributions of the 'direct', the several 'indirect' ${ }^{19}$ and 'hyperdirect' projections ${ }^{14}$, and different cell types ${ }^{151}$ to the dysfunctional output signals in Parkinson's disease. Similarly, it is at a different level of 
discussion to the current debate over whether the distortion of basal ganglia output in Parkinson's disease and animal models is best characterized by disturbances of rate-coding or pattern-coding ${ }^{140},{ }^{144},{ }^{152}$. The current analysis simply acknowledges that - although patterns of intrinsic connectivity are viewed differently now - it is within the 'direct', 'indirect' and 'hyperdirect' circuits of mainly caudolateral sensorimotor territories of the basal ganglia nuclei that a chronic lack of dopamine causes both the principal distorting pathological output from the basal ganglia and deficits in the selection of habitual responses in patients with Parkinson's disease. Clearly, the ongoing research effort to discover the intrinsic mechanisms underlying sensorimotor dysfunction in the basal ganglia is vitally important, particularly with regard to the discovery of novel therapeutic advances.

The importance of the current proposal is that it provides a higher, systems-level account of the functional architecture of the basal ganglia by taking into account that different regions of a common structural architecture seem to be crucial for goal-directed and habitual control. As the loss of dopamine is greatest in territories associated with habitual control, the main symptoms of Parkinson's disease should reflect a relative reduction in the expression of habits. The current analysis also connects with an extensive literature ${ }^{115},{ }^{116},{ }^{121}{ }^{125}$ that has characterized the comparative loss of automatic and implicit control mechanisms in patients with Parkinson's disease. Moreover, because goal-directed and habit systems operate through a 'final common motor path', the distorting output from stimulus-response habit circuits must be overridden for goal-directed control to be expressed. Consequently, the reports that surgical lesions ameliorate behavioural disturbances associated with the disease $^{142}$ become less paradoxical.

However, important issues remain. First, throughout our discussion of behavioural control we use formal terminology from the learning theory literature ('goal-directed' and 'habit'), and wherever possible restrict our review of the animal and human literature to studies that include the formal tests of reinforcer devaluation and/or contingency degradation $63,69,72,81$. However, in the clinical, psychological, animal behaviour and neuroscience literatures, different terminologies are used to refer to what might turn out to be the same - or similar - concepts. Thus, the terms 'conscious', 'voluntary', 'explicit', 'internally generated' and 'controlled', may often have substantial overlap with the concept of goal-directed control ${ }^{83}$. Alternatively, ideas encapsulated by the terms 'unconscious', 'involuntary', 'implicit', 'externally generated' and 'automatic', may all denote behaviour that is mainly under habitual control ${ }^{83}$. Future investigations will determine the degree of overlap between these concepts and how far they need to be refined. In part, this will benefit from the continuing development of formal tests of goal-directed and habitual control in both human and animal studies $^{65}$. However, the results of these investigations will have serious implications for how the behavioural deficits of patients with basal ganglia diseases, including Parkinson's disease, will be interpreted, and how such interpretations are associated with neural processing in the different functional territories of the basal ganglia. Furthermore, our analysis makes different predictions for the different therapeutic interventions used for Parkinson's disease. On the one hand, dopamine replacement therapies might be expected to reinstate some degree of habitual sensorimotor control ${ }^{153},{ }^{154}$, whereas this should be impossible following the bilateral destruction or tonic suppression of sensorimotor loops in the basal ganglia by surgical interventions ${ }^{144}$. As has been mentioned elsewhere ${ }^{118}$, experiments that test the effects of a range of therapeutic interventions on the performance of formally determined goal-directed and habitual tasks by patients with Parkinson's disease are warranted. Initial studies that were limited to a few patients are encouraging in that lesions of basal ganglia output systems in patients with Parkinson's disease improved basic motor features, whereas new learning and complex motor performance remained impaired $^{155}$. The importance of formal testing is also highlighted by a recent report that habit formation in an instrumental conflict task was preserved in patients with Parkinson's 
disease ${ }^{156}$. Unexpectedly, however, in the condition in which patients were assumed to be operating in habit mode their reaction times were longer than when their performance was goal-directed. It is therefore possible that conflict-induced habit formation may be different from that induced by extensive training (which results in quicker habitual responding) ${ }^{83},{ }^{157}$. A further important issue for future research will be to determine whether executive difficulties associated with initiating and executing goal-directed performance are due to the primary disease state (that is, the loss of dopamine from goal-directed circuits ${ }^{126}$ ) or because goal-directed control is overwhelmed by the absence of automatic control routines that are normally provided by the stimulus-response habit systems ${ }^{116},{ }^{121}$. In the case of future animal models, it will be important to mimic the loss of dopamine from sensorimotor territories of the basal ganglia seen in patients with Parkinson's disease ${ }^{119}$, rather than creating near-complete loss of dopamine, as is common in many of the current models. The same would be true for other conditions in which differential impairment across the functional subregions of the striatum may have taken place - for example, in patients with different phenotypes of Huntington's disease and in patients with Tourette's syndrome with or without obsessive-compulsive disorder ${ }^{158},{ }^{159}$. It is equally important to investigate the consequences of differential loss of dopamine between brain hemispheres and the role of the less affected hemisphere in therapeutic reinstatement of behavioural control. Indeed, the manner in which the basal ganglia operate bilaterally in normal and pathological states has been sadly neglected and should be an important focus of future research.

\section{Acknowledgments}

This article arose as a result of a meeting ('From movement to behaviour and emotions: role of the basal ganglia') held in December 2008 at the Centro Internacional de Restauracion Neurologica (CIREN) in Havana, Cuba. The meeting was organized by the CIREN and the Neuroscience Department, CIMA, University of Navarra, Pamplona, Spain, and sponsored by private donations. Authors are grateful to J. Alvarez, President of CIREN, and D. Frontera and family for their support and contribution to the project's success. P.R. was supported by a European Framework 7 grant and the Wellcome Trust, and J.A.O. by the University of Navarra-Union Temporal de Empresas (UTE) agreement during the preparation of this article. We thank B. Balleine for providing us with a high resolution copy of figure 3, and C. Juri and J. Arbizu for the PET images in figure 4.

\section{Glossary}

Basal ganglia

Striatum

Parkinsonian state

Dyskinetic state

Hemiballismus

Instrumental learning
One of the fundamental processing units of the vertebrate brain. In mammals they comprise the striatum, globus pallidus, substantia nigra and subthalamic nucleus.

The principal input nucleus of the basal ganglia consisting of the caudate nucleus and putamen.

A state characterized by akinesia, bradykinesia and tremor associated in the initial stages with a differential loss of dopamine from the sensorimotor territories of the striatum.

A state characterized by involuntary, repetitive body movements.

A movement disorder that is characterized by large-amplitude involuntary flinging motions of the extremities.

Learning in which a reinforcing outcome is contingent on the performance (or withholding) of a particular behaviour. Thus, the subject's response is 'instrumental' in producing an outcome (typically a food reward). 
Associative learning

Fixed ratio schedules

Interval schedules

Set shifting

6-hydroxydopamine

lesion model of

Parkinson's disease

Oscillations

Abulia

Poverty of thought
Any learning process in which a new response becomes associated with a particular stimulus. In animal behaviour it generally denotes learning that occurs through classical and instrumental conditioning.

(Often abbreviated to FR schedules.) Situations in which there is a fixed relationship between responses and outcomes. For example, in an FR3 schedule, every third response is reinforced.

Reinforcement is delivered with the first response following a fixed or variable interval, making the association between response and outcome much weaker.

The ability to modify ongoing behaviour in response to changing goals or environmental experiences.

A neurotoxin that, when administered to the substantia nigra of rodents, causes degeneration of the ascending nigrostriatal dopaminergic pathway, thereby mimicking the loss of dopaminergic innervation in Parkinson's disease.

(Referring here to oscillations in Parkinson's disease.) Resting tremor that is thought to be related to the increased levels of synchronous neuronal activity observed within the basal ganglia of patients with Parkinson's disease and in animal models of the disease.

A condition characterized by a reduction in goal-directed verbal, motor, cognitive and emotional behaviours and that is associated with focal lesions of the basal ganglia.

A form of 'psychic akinesia' in which patients are generally apathetic and exhibit a profound lack of 'will'.

\section{References}

1. Ferrier, D. The Functions of the Brain. Putnam's Sons; New York: 1876.

2. Penney JB Jr, Young AB. Striatal inhomogeneities and basal ganglia function. Mov. Disord. 1986; 1:3-15. [PubMed: 2848190]

3. Albin RL, Young AB, Penney JB. The functional anatomy of basal ganglia disorders. Trends Neurosci. 1989; 12:366-375. [PubMed: 2479133]

4. Chevalier G, Deniau JM. Disinhibition as a basic process in the expression of striatal functions. Trends Neurosci. 1990; 13:277-281. [PubMed: 1695403] This review introduced a conceptual development in suggesting that a pause in neuronal firing in basal ganglia output nuclei disinhibits efferent targets and is the major physiological mechanism by which the basal ganglia exert their effects on behaviour.

5. Gerfen, CR.; Wilson, CJ. Handbook of Chemical Neuroanatomy. Swanson, LW.; Bjorklund, A.; Hokfelt, T., editors. Vol. Vol 12. Elsevier; Amsterdam: 1996. p. 371-468.

6. DeLong MR. Primate models of movement disorders of basal ganglia origin. Trends Neurosci. 1990; 13:281-285. [PubMed: 1695404] A classic review of the basal ganglia pathophyisiological model and the concepts on which it is based.

7. Gerfen CR, et al. D1 and D2 dopamine receptor regulated gene expression of striatonigral and striatopallidal neurons. Science. 1990; 250:1429-1431. [PubMed: 2147780]

8. Crossman AR. Primate models of dyskinesia: the experimental approach to the study of basal ganglia-related involuntary movement disorders. Neuroscience. 1987; 21:1-40. [PubMed: 2955248] 
9. Bevan MD, Bolam JP, Crossman AR. Convergent synaptic input from the neostriatum and the subthalamus onto identified nigrothalamic neurons in the rat. Eur. J. Neurosci. 1994; 6:320-334. [PubMed: 8019671]

10. Redgrave P. Basal ganglia. Scholarpedia. 2007; 2:1825.

11. Wu Y, Richard S, Parent A. The organization of the striatal output system: a single-cell juxtacellular labeling study in the rat. Neurosci. Res. 2000; 38:49-62. [PubMed: 10997578]

12. Matamales M, et al. Striatal medium-sized spiny neurons: identification by nuclear staining and study of neuronal subpopulations in BAC transgenic mice. PLoS ONE. 2009; 4:e4770. [PubMed: 19274089]

13. Hartmann-von Monakow KH, Akert K, Kunzle H. Projections of the precentral motor cortex and other cortical areas of the frontal lobe to the subthalamic nucleus in the monkey. Exp. Brain Res. 1978; 33:395-403. [PubMed: 83239]

14. Nambu A, Tokuno H, Takada M. Functional significance of the cortico-subthalamopallidal 'hyperdirect' pathway. Neurosci. Res. 2002; 43:111-117. [PubMed: 12067746]

15. Lanciego JL, et al. Thalamic innervation of striatal and subthalamic neurons projecting to the rat entopeduncular nucleus. Eur. J. Neurosci. 2004; 19:1267-1277. [PubMed: 15016084]

16. Feger J, Bevan M, Crossman AR. The projections from the parafascicular thalamic nucleus to the subthalamic nucleus and the striatum arise from separate neuronal populations - a comparison with the corticostriatal and corticosubthalamic efferents in a retrograde fluorescent doublelabelling study. Neuroscience. 1994; 60:125-132. [PubMed: 8052406]

17. Coizet V, et al. Short-latency visual input to the subthalamic nucleus is provided by the midbrain superior colliculus. J. Neurosci. 2009; 29:5701-5709. [PubMed: 19403836]

18. Mena-Segovia J, Bolam JP, Magill PJ. Pedunculopontine nucleus and basal ganglia: distant relatives or part of the same family? Trends Neurosci. 2004; 27:585-588. [PubMed: 15374668]

19. Smith Y, Bevan MD, Shink E, Bolam JP. Microcircuitry of the direct and indirect pathways of the basal ganglia. Neuroscience. 1998; 86:353-387. [PubMed: 9881853]

20. Miwa H, Fuwa T, Nishi K, Kondo T. Subthalamo-pallido-striatal axis: a feedback system in the basal ganglia. Neuroreport. 2001; 12:3795-3798. [PubMed: 11726797]

21. Shink E, Bevan MD, Bolam JP, Smith Y. The subthalamic nucleus and the external pallidum: two tightly interconnected structures that control the output of the basal ganglia in the monkey. Neuroscience. 1996; 73:335-357. [PubMed: 8783253]

22. Kita, H. Gaba And The Basal Ganglia: From Molecules To Systems. Tepper, J.; Absercrombie, E.; Bolam, JP., editors. Elsevier; Amsterdam: 2007. p. 111-133.

23. Bevan MD, Booth PAC, Eaton SA, Bolam JP. Selective innervation of neostriatal interneurons by a subclass of neuron in the globus pallidus of the rat. J. Neurosci. 1998; 18:9438-9452. [PubMed: 9801382]

24. Kita H, Tokuno H, Nambu A. Monkey globus pallidus external segment neurons projecting to the neostriatum. Neuroreport. 1999; 10:1467-1472. [PubMed: 10380964]

25. McGeorge AJ, Faull RLM. The organization of the projection from the cerebral cortex to the striatum in the rat. Neuroscience. 1989; 29:503-537. [PubMed: 2472578]

26. Romanelli P, Esposito V, Schaal DW, Heit G. Somatotopy in the basal ganglia: experimental and clinical evidence for segregated sensorimotor channels. Brain Res. Rev. 2005; 48:112-128. [PubMed: 15708631]

27. Wiesendanger E, Clarke S, Kraftsik R, Tardif E. Topography of cortico-striatal connections in man: anatomical evidence for parallel organization. Eur. J. Neurosci. 2004; 20:1915-1922. [PubMed: 15380013]

28. Nakano K, Kayahara T, Tsutsumi T, Ushiro H. Neural circuits and functional organization of the striatum. J. Neurol. 2000; 247:V1-V15. [PubMed: 11081799]

29. Alexander GE, DeLong MR, Strick PL. Parallel organization of functionally segregated circuits linking basal ganglia and cortex. Ann. Rev. Neurosci. 1986; 9:357-381. [PubMed: 3085570] The classic and first description of the re-entrant looped architecture by which the basal ganglia interact with external structures.

30. McHaffie JG, Stanford TR, Stein BE, Coizet V, Redgrave P. Subcortical loops through the basal ganglia. Trends Neurosci. 2005; 28:401-407. [PubMed: 15982753] 
31. Bolam, JP.; Bennett, BD. Molecular and Cellular Mechanims of Neostriatal Function. Ariano, MA.; Surmeier, DJ., editors. R. G. Landes Co.; Texas: 1995. p. 1-19.

32. Gillies A, Willshaw D. Models of the subthalamic nucleus: the importance of intranuclear connectivity. Med. Eng. Phys. 2004; 26:723-732. [PubMed: 15564109]

33. Benarroch EE. Subthalamic nucleus and its connections: anatomic substrate for the network effects of deep brain stimulation. Neurology. 2008; 70:1991-1995. [PubMed: 18490619]

34. Parent M, Parent A. The microcircuitry of primate subthalamic nucleus. Parkinsonism Relat. Disord. 2007; 13:S292-S295. [PubMed: 18267252]

35. Nakano K. Neural circuits and topographic organization of the basal ganglia and related regions. Brain Dev. 2000; 22:S5-S16. [PubMed: 10984656]

36. Voorn P, Vanderschuren LJ, Groenewegen HJ, Robbins TW, Pennartz CM. Putting a spin on the dorsal-ventral divide of the striatum. Trends Neurosci. 2004; 27:468-474. [PubMed: 15271494]

37. Draganski B, et al. Evidence for segregated and integrative connectivity patterns in the human basal ganglia. J. Neurosci. 2008; 28:7143-7152. [PubMed: 18614684]

38. Lehericy S, et al. 3-D diffusion tensor axonal tracking shows distinct SMA and pre-SMA projections to the human striatum. Cereb. Cortex. 2004; 14:1302-1309. [PubMed: 15166103]

39. Doron O, Goelman G. Evidence for asymmetric intra substantia nigra functional connectivityapplication to basal ganglia processing. Neuroimage. 2010; 49:2940-2946. [PubMed: 19944765]

40. Krout KE, Belzer RE, Loewy AD. Brainstem projections to midline and intralaminar thalamic nuclei of the rat. J. Comp. Neurol. 2002; 448:53-101. [PubMed: 12012375]

41. Krout KE, Loewy AD, Westby GWM, Redgrave P. Superior colliculus projections to midline and intralaminar thalamic nuclei of the rat. J. Comp. Neurol. 2001; 431:198-216. [PubMed: 11170000]

42. Krout KE, Loewy AD. Periaqueductal gray matter projections to midline and intralaminar thalamic nuclei of the rat. J. Comp. Neurol. 2000; 424:111-141. [PubMed: 10888743]

43. Erro E, Lanciego JL, Gimenez-Amaya JM. Relationships between thalamostriatal neurons and pedunculopontine projections to the thalamus: a neuroanatomical tract-tracing study in the rat. Exp. Brain Res. 1999; 127:162-170. [PubMed: 10442408]

44. Bjorklund A, Dunnett SB. Dopamine neuron systems in the brain: an update. Trends Neurosci. 2007; 30:194-202. [PubMed: 17408759]

45. Matsuda W, et al. Single nigrostriatal dopaminergic neurons form widely spread and highly dense axonal arborizations in the neostriatum. J. Neurosci. 2009; 29:444-453. [PubMed: 19144844]

46. Smith Y, Lavoie B, Dumas J, Parent A. Evidence for a distinct nigropallidal dopaminergic projection in the squirrel monkey. Brain Res. 1989; 482:381-386. [PubMed: 2565144]

47. Cragg SJ, Baufreton J, Xue Y, Bolam JP, Bevan MD. Synaptic release of dopamine in the subthalamic nucleus. Eur. J. Neurosci. 2004; 20:1788-1802. [PubMed: 15380000]

48. Grace AA. Phasic versus tonic dopamine release and the modulation of dopamine system responsivity: a hypothesis for the etiology of schizophrenia. Neuroscience. 1991; 41:1-24. [PubMed: 1676137]

49. Redgrave P, Prescott T, Gurney KN. The basal ganglia: a vertebrate solution to the selection problem? Neuroscience. 1999; 89:1009-1023. [PubMed: 10362291] Ageneral description of the mechanisms and computational requirements of selection performed by the basal ganglia.

50. Mink JW. The basal ganglia: focused selection and inhibition of competing motor programs. Prog. Neurobiol. 1996; 50:381-425. [PubMed: 9004351]

51. Hikosaka O, Takikawa Y, Kawagoe R. Role of the basal ganglia in the control of purposive saccadic eye movements. Physiol. Rev. 2000; 80:953-978. [PubMed: 10893428]

52. Redgrave P, Gurney K. The short-latency dopamine signal: a role in discovering novel actions? Nature Rev. Neurosci. 2006; 7:967-975. [PubMed: 17115078]

53. Redgrave P, Gurney K, Reynolds J. What is reinforced by phasic dopamine signals? Brain Res. Rev. 2008; 58:322-339. [PubMed: 18055018]

54. Schultz W. Behavioral theories and the neurophysiology of reward. Annu. Rev. Psychol. 2006; 57:87-115. [PubMed: 16318590] 
55. Alexander GE, DeLong MR. Microstimulation of the primate neurostriatum. II. Somatotopic organization of striatal microexcitable zones and their relation to neuronal response properties. J. Neurophysiol. 1985; 53:1417-1430. [PubMed: 4009227]

56. Kimura M. Behaviorally contingent property of movement-related activity of the primate putamen. J. Neurophysiol. 1990; 63:1277-1296. [PubMed: 2358877]

57. Flaherty AW, Graybiel AM. Two input systems for body representation in the primate striatal matrix: experimental evidence in the squirrel monkey. J. Neurosci. 1993; 13:1120-1137. [PubMed: 7680067]

58. Hikosaka O, Sakamoto M, Usui S. Functional properties of monkey caudate neurons. I. Activities related to saccadic eye movements. J. Neurophysiol. 1989; 61:780-798. [PubMed: 2723720]

59. Hikosaka O, Sakamoto M, Usui S. Functional properties of monkey caudate neurons II. Visual and auditory responses. J. Neurophysiol. 1989; 61:799-813. [PubMed: 2723721]

60. Tremblay L, Hollerman JR, Schultz W. Modifications of reward expectation-related neuronal activity during learning in primate striatum. J. Neurophysiol. 1998; 80:964-977. [PubMed: 9705482]

61. Scholz VH, et al. Laterality, somatotopy and reproducibility of the basal ganglia and motor cortex during motor tasks. Brain Res. 2000; 879:204-215. [PubMed: 11011024]

62. Gerardin E, et al. Foot, hand, face and eye representation in the human striatum. Cereb. Cortex. 2003; 13:162-169. [PubMed: 12507947]

63. Dickinson A. The 28th Bartlett Memorial Lecture Causal learning: an associative analysis. Q. J. Exp. Psychol. B. 2001; 54:3-25. [PubMed: 11216300]

64. Balleine BW, Lijeholm M, Ostlund SB. The integrative function of the basal ganglia in instrumental conditioning. Behav. Brain Res. 2009; 199:43-52. [PubMed: 19027797]

65. Balleine BW, O'Doherty JP. Human and rodent homologies in action control: corticostriatal determinants of goal-directed and habitual action. Neuropsychopharmacology. 2009; 35:48-69. [PubMed: 19776734] This paper provides well-written and clearly explained views about the role of the basal ganglia in the control of human and rodent behaviour.

66. Yin HH, Knowlton BJ. The role of the basal ganglia in habit formation. Nature Rev. Neurosci. 2006; 7:464-476. [PubMed: 16715055] An excellent review of the role of the basal ganglia in habitual and goal-directed control.

67. Thorndike, EL. Animal Intelligence. Macmillan; New York: 1911.

68. Spence, KW. Behavior Theory and Conditioning. Yale Univ. Press; New Haven: 1956.

69. Dickinson A, Balleine B. Motivational control of goal-directed action. Anim. Learn. Behav. 1994; 22:1-18.

70. Adams CD, Dickinson A. Instrumental responding following reinforcer devaluation. Q. J. Exp. Psychol. 1981; 33:109-121.

71. Hammond LJ. The effect of contingency upon the appetitive conditioning of free-operant behavior. J. Exp. Anal. Behav. 1980; 34:297-304. [PubMed: 16812191]

72. Balleine BW, Dickinson A. Goal-directed instrumental action: contingency and incentive learning and their cortical substrates. Neuropharmacology. 1998; 37:407-419. [PubMed: 9704982]

73. Horvitz JC. Stimulus-response and response-outcome learning mechanisms in the striatum. Behav. Brain Res. 2009; 199:129-140. [PubMed: 19135093]

74. Schwabe L, Wolf OT, Oitzl MS. Memory formation under stress: quantity and quality. Neurosci. Biobehav. Rev. 2010; 34:584-591. [PubMed: 19931555]

75. Hikosaka O, Isoda M. Switching from automatic to controlled behavior: cortico-basal ganglia mechanisms. Trends Cogn. Sci. 2010; 14:154-161. [PubMed: 20181509] An important recent analysis of the neural mechanisms responsible for switching between automatic and controlled behaviour.

76. Monsell S. Task switching. Trends Cogn. Sci. 2003; 7:134-140. [PubMed: 12639695]

77. Dickinson A, Nicholas DJ, Adams CD. The effect of the instrumental training contingency on susceptibility to reinforcer devaluation. Q. J. Exp. Psychol. 1983; 35:35-51. 
78. Heuer H, Spijkers W, Kiesswetter E, Schmidtke V. Effects of sleep loss, time of day, and extended mental work on implicit and explicit learning of sequences. J. Exp. Psychol. Appl. 1998; 4:139_ 162. [PubMed: 11541529]

79. Dias-Ferreira E, et al. Chronic stress causes frontostriatal reorganization and affects decisionmaking. Science. 2009; 325:621-625. [PubMed: 19644122]

80. Mazzoni P, Wexler NS. Parallel explicit and implicit control of reaching. PLoS ONE. 2009; 4:e7557. [PubMed: 19847295]

81. Balleine BW, Ostlund SB. Still at the choice-point: action selection and initiation in istrumental conditioning. encoding. Ann. NY Acad. Sci. 2007; 1104:147-171. [PubMed: 17360797]

82. Daw ND, Niv Y, Dayan P. Uncertainty-based competition between prefrontal and dorsolateral striatal systems for behavioral control. Nature Neurosci. 2005; 8:1704-1711. [PubMed: 16286932]

83. Schneider W, Chein JM. Controlled \& automatic processing: behavior, theory, and biological mechanisms. Cogn. Sci. 2003; 27:525-559. An excellent review of the differences between controlled and automatic processing in humans.

84. Yin HH, Knowlton BJ, Balleine BW. Lesions of dorsolateral striatum preserve outcome expectancy but disrupt habit formation in instrumental learning. Eur. J. Neurosci. 2004; 19:181189. [PubMed: 14750976]

85. Yin HH, Knowlton BJ, Balleine BW. Blockade of NMDA receptors in the dorsomedial striatum prevents action-outcome learning in instrumental conditioning. Eur. J. Neurosci. 2005; 22:505512. [PubMed: 16045503]

86. Yin HH, Ostlund SB, Knowlton BJ, Balleine BW. The role of the dorsomedial striatum in instrumental conditioning. Eur. J. Neurosci. 2005; 22:513-523. [PubMed: 16045504]

87. Yin HH, Knowlton BJ, Balleine BW. Inactivation of dorsolateral striatum enhances sensitivity to changes in the action-outcome contingency in instrumental conditioning. Behav. Brain Res. 2006; 166:189-196. [PubMed: 16153716]

88. Miyachi S, Hikosaka O, Miyashita K, Karadi Z, Rand MK. Differential roles of monkey striatum in learning of sequential hand movement. Exp. Brain Res. 1997; 115:1-5. [PubMed: 9224828]

89. Miyachi S, Hikosaka O, Lu XF. Differential activation of monkey striatal neurons in the early and late stages of procedural learning. Exp. Brain Res. 2002; 146:122-126. [PubMed: 12192586]

90. Monchi O, Petrides M, Petre V, Worsley K, Dagher A. Wisconsin Card Sorting revisited: distinct neural circuits participating in different stages of the task identified by event-related functional magnetic resonance imaging. J. Neurosci. 2001; 21:7733-7741. [PubMed: 11567063]

91. Monchi O, Petrides M, Strafella AP, Worsley KJ, Doyon J. Functional role of the basal ganglia in the planning and execution of actions. Ann. Neurol. 2006; 59:257-264. [PubMed: 16437582]

92. Lewis SJG, Dove A, Robbins TW, Barker RA, Owen AM. Striatal contributions to working memory: a functional magnetic resonance imaging study in humans. Eur. J. Neurosci. 2004; 19:755-760. [PubMed: 14984425]

93. Jueptner M, Frith CD, Brooks DJ, Frackowiak RS, Passingham RE. Anatomy of motor learning. II. Subcortical structures and learning by trial and error. J. Neurophysiol. 1997; 77:1325-1337. [PubMed: 9084600]

94. Lehericy $\mathrm{S}$, et al. Distinct basal ganglia territories are engaged in early and advanced motor sequence learning. Proc. Natl Acad. Sci.USA. 2005; 102:12566-12571. [PubMed: 16107540] An early study in humans indicating that different striatal regions become engaged during different phases of motor learning.

95. Tanaka SC, Balleine BW, O'Doherty JP. Calculating consequences: brain systems that encode the causal effects of actions. J. Neurosci. 2008; 28:6750-6755. [PubMed: 18579749]

96. Tricomi E, Balleine BW, O’Doherty JP. A specific role for posterior dorsolateral striatum in human habit learning. Eur. J. Neurosci. 2009; 29:2225-2232. [PubMed: 19490086]

97. Gurney K, Prescott TJ, Redgrave P. A computational model of action selection in the basal ganglia. I. A new functional anatomy. Biol. Cybern. 2001; 84:401-410. [PubMed: 11417052]

98. Gurney K, Prescott TJ, Redgrave P. A computational model of action selection in the basal ganglia. II. Analysis and simulation of behaviour. Biol. Cybern. 2001; 84:411-423. [PubMed: 11417053] 
99. Humphries MD, Stewart RD, Gurney KN. A physiologically plausible model of action selection and oscillatory activity in the basal ganglia. J. Neurosci. 2006; 26:12921-12942. [PubMed: 17167083]

100. Prescott TJ, Gonzalez FMM, Gurney K, Humphries MD, Redgrave P. A robot model of the basal ganglia: behavior and intrinsic processing. Neural Netw. 2006; 19:31-61. [PubMed: 16153803]

101. Singh, SP.; Barto, AG.; Chentanez, N. Advances in Neural Information Processing Systems. Saul, LK.; Weiss, H.; Bottou, L., editors. MIT Press; Cambridge, Massachusetts: 2005. p. 1281-1288.

102. Doubell TP, Skaliora I, Baron J, King AJ. Functional connectivity between the superficial and deeper layers of the superior colliculus: an anatomical substrate for sensorimotor integration. J. Neurosci. 2003; 23:6596-6607. [PubMed: 12878701]

103. Sommer MA, Wurtz RH. Composition and topographic organization of signals sent from the frontal eye field to the superior colliculus. J. Neurophysiol. 2000; 83:1979-2001. [PubMed: 10758109]

104. McHaffie JG, Thomson CM, Stein BE. Corticotectal and corticostriatal projections from the frontal eye fields of the cat: an anatomical examination using WGA-HRP. Somatosens Mot. Res. 2001; 18:117-130. [PubMed: 11534775]

105. Gitelman DR, Parrish TB, Friston KJ, Mesulam MM. Functional anatomy of visual search: regional segregations within the frontal eye fields and effective connectivity of the superior colliculus. Neuroimage. 2002; 15:970-982. [PubMed: 11906237]

106. Takakusaki K, Okumura T. Neurobiological basis of controlling posture and locomotion. Adv. Robot. 2008; 22:1629-1663.

107. Pavese N, Brooks DJ. Imaging neurodegeneration in Parkinson's disease. Biochim. Biophys. Acta. 2009; 1792:722-729. [PubMed: 18992326]

108. Morrish PK, Sawle GV, Brooks DJ. Clinical and [18F] dopa PET findings in early Parkinson's disease. J. Neurol. Neurosurg. Psychiatr. 1995; 59:597-600. [PubMed: 7500096]

109. Kish SJ, Shannak K, Hornykiewicz O. Uneven pattern of dopamine loss in the striatum of patients with idiopathic Parkinson's disease. Pathophysiologic and clinical implications. N. Engl. J. Med. 1988; 318:876-880. [PubMed: 3352672] A key paper indicating a differential loss of dopamine from the sensorimotor territories of the caudal putamen in patients with Parkinson's disease.

110. Fearnley JM, Lees AJ. Ageing and Parkinson's disease: substantia nigra regional selectivity. Brain. 1991; 114:2283-2301. [PubMed: 1933245]

111. Marsden CD. The mysterious motor function of the basal ganglia: the Robert Wartenberg Lecture. Neurology. 1982; 32:514-539. [PubMed: 7200209] Classic, fundamental appraisal of the origin of movement disorders in early Parkinson's disease.

112. Rodriguez-Oroz MC, et al. Initial clinical manifestations of Parkinson's disease: features and pathophysiological mechanisms. Lancet Neurol. 2009; 8:1128-1139. [PubMed: 19909911]

113. Schwab RS, Chafetz ME, Walker S. Control of two simultaneous voluntary motor acts in normals and in parkinsonism. AMA Arch. Neurol. Psychiatry. 1954; 72:591-598.

114. Hoshiyama M, Kaneoke Y, Koike Y, Takahashi A, Watanabe S. Hypokinesia of associated movement in Parkinson's disease: a symptom in early stages of the disease. J. Neurol. 1994; 241:517-521. [PubMed: 7798998]

115. Knowlton BJ, Mangels JA, Squire LR. A neostriatal habit learning system in humans. Science. 1996; 273:1399-1402. [PubMed: 8703077]

116. Hallett M. The intrinsic and extrinsic aspects of freezing of gait. Mov. Disord. 2008; 23:S439S443. [PubMed: 18668625]

117. Wu T, Chan P, Hallett M. Effective connectivity of neural networks in automatic movements in Parkinson's disease. Neuroimage. 2010; 49:2581-2587. [PubMed: 19853664]

118. Moody TD, Chang GY, Vanek ZF, Knowlton BJ. Concurrent discrimination learning in Parkinson's disease. Behav. Neurosci. 2010; 124:1-8. [PubMed: 20141275]

119. Faure A, Haberland U, Conde F, El Massioui N. Lesion to the nigrostriatal dopamine system disrupts stimulus-response habit formation. J. Neurosci. 2005; 25:2771-2780. [PubMed: 15772337]

120. Benecke R, Rothwell JC, Dick JP, Day BL, Marsden CD. Performance of simultaneous movements in patients with Parkinson's disease. Brain. 1986; 109:739-757. [PubMed: 3730813] 
121. Nieuwboer A, Rochester L, Muncks L, Swinnen SP. Motor learning in Parkinson's disease: limitations and potential for rehabilitation. Parkinsonism Relat. Disord. 2009; 15:S53-S58. [PubMed: 20083008]

122. Okuma Y, Yanagisawa N. The clinical spectrum of freezing of gait in Parkinson's disease. Mov. Disord. 2008; 23:S426-S430. [PubMed: 18668623]

123. Benecke R, Rothwell JC, Dick JP, Day BL, Marsden CD. Disturbance of sequential movements in patients with Parkinson's disease. Brain. 1987; 110:361-379. [PubMed: 3567527]

124. Stelmach GE, Worringham CJ, Strand EA. Movement preparation in Parkinson's disease. The use of advance information. Brain. 1986; 109:1179-1194. [PubMed: 3790973]

125. Doyon J. Motor sequence learning and movement disorders. Curr. Opin. Neurol. 2008; 21:478483. [PubMed: 18607210]

126. Nandhagopal R, et al. Longitudinal progression of sporadic Parkinson's disease: a multi-tracer positron emission tomography study. Brain. 2009; 132:2970-2979. [PubMed: 19690093]

127. Rogers MA, Phillips JG, Bradshaw JL, Iansek R, Jones D. Provision of external cues and movement sequencing in Parkinson's disease. Motor Control. 1998; 2:125-132. [PubMed: 9644283]

128. Jahanshahi M, Brown RG, Marsden CD. Simple and choice reaction time and the use of advance information for motor preparation in Parkinson's disease. Brain. 1992; 115:539-564. [PubMed: 1606481]

129. Mesulam MM. From sensation to cognition. Brain. 1998; 121:1013-1052. [PubMed: 9648540]

130. Lozza A, Pepin JL, Rapisarda G, Moglia A, Delwaide PJ. Functional changes of brainstem reflexes in Parkinson's disease. Conditioning of the blink reflex R 2 component by paired and index finger stimulation. J. Neural Transm. 1997; 104:679-687. [PubMed: 9444567]

131. Fanselow MS, Poulos AM. The neuroscience of mammalian associative learning. Annu. Rev. Psychol. 2005; 56:207-234. [PubMed: 15709934]

132. Cardinal RN, Parkinson JA, Hall J, Everitt BJ. Emotion and motivation: the role of the amygdala, ventral striatum, and prefrontal cortex. Neurosci. Biobehav. Rev. 2002; 26:321-352. [PubMed: 12034134]

133. DeLong MR, Wichmann T. Circuits and circuit disorders of the basal ganglia. Arch. Neurol. 2007; 64:20-24. [PubMed: 17210805]

134. Obeso JA, et al. The basal ganglia in Parkinson's disease: current concepts and unexplained observations. Ann. Neurol. 2008; 64:S30-S46. [PubMed: 19127584]

135. Filion M, Tremblay L. Abnormal spontaneous activity of globus pallidus neurons in monkeys with MPTP-induced parkinsonism. Brain Res. 1991; 547:142-151. [PubMed: 1677607]

136. Rodriguez-Oroz MC, et al. The subthalamic nucleus in Parkinson's disease: somatotopic organization and physiological characteristics. Brain. 2001; 124:1777-1790. [PubMed: 11522580]

137. Levy R, Hutchison WD, Lozano AM, Dostrovsky JO. Synchronized neuronal discharge in the basal ganglia of parkinsonian patients is limited to oscillatory activity. J. Neurosci. 2002; 22:2855-2861. [PubMed: 11923450]

138. Wichmann T, Soares J. Neuronal firing before and after burst discharges in the monkey basal ganglia is predictably patterned in the normal state and altered in parkinsonism. J. Neurophysiol. 2006; 95:2120-2133. [PubMed: 16371459]

139. Lopez-Azcarate $J$, et al. Coupling between $\beta$ and high-frequency activity in the human subthalamic nucleus may be a pathophysiological mechanism in Parkinson's disease. J. Neurosci. 2010; 30:6667-6677. [PubMed: 20463229]

140. Brown P, Marsden CD. What do the basal ganglia do? Lancet. 1998; 351:1801-1804. [PubMed: 9635969]

141. Hallett M, Khoshbin S. A physiological mechanism of bradykinesia. Brain. 1980; 103:301-314. [PubMed: 7397480]

142. Marsden CD, Obeso JA. The function of the basal ganglia and the paradox of stereotaxic surgery in Parkinson's disease. Brain. 1994; 117:877-897. [PubMed: 7922472] A classic approach to the enigma of how the basal ganglia output can be destroyed without deteriorating the movement further in patients with Parkinson's disease. 
143. Rivlin-Etzion M, et al. Low-pass filter properties of basal ganglia-cortical-muscle loops in the normal and MPTP primate model of parkinsonism. J. Neurosci. 2008; 28:633-649. [PubMed: 18199764]

144. Brown P, Eusebio A. Paradoxes of functional neurosurgery: clues from basal ganglia recordings. Mov. Disord. 2008; 23:12-20. [PubMed: 17999423]

145. Vitek JL, et al. Microelectrode-guided pallidotomy: technical approach and its application in medically intractable Parkinson's disease. J. Neurosurg. 1998; 88:1027-1043. [PubMed: 9609298]

146. Vijayaraghavan L, Krishnamoorthy ES, Brown RG, Trimble MR. Abulia: a delphi survey of British neurologists and psychiatrists. Mov. Disord. 2002; 17:1052-1057. [PubMed: 12360558]

147. Habib M. Athymhormia and disorders of motivation in Basal Ganglia disease. J. Neuropsychiatry Clin. Neurosci. 2004; 16:509-524. [PubMed: 15616180]

148. Pedersen KF, Alves G, Aarsland D, Larsen JP. Occurrence and risk factors for apathy in Parkinson disease: a 4-year prospective longitudinal study. J. Neurol. Neurosurg. Psychiatr. 2009; 80:1279-1282. [PubMed: 19864662]

149. Voon V, et al. Chronic dopaminergic stimulation in Parkinson's disease: from dyskinesias to impulse control disorders. Lancet Neurol. 2009; 8:1140-1149. [PubMed: 19909912]

150. Niv Y, Daw ND, Joel D, Dayan P. Tonic dopamine: opportunity costs and the control of response vigor. Psychopharmacology (Berlin). 2007; 191:507-520. [PubMed: 17031711]

151. Tepper JM, Bolam JP. Functional diversity and specificity of neostriatal interneurons. Curr. Opin. Neurobiol. 2004; 14:685-692. [PubMed: 15582369]

152. Bergman, H.; Wichmann, T.; Karmon, B.; DeLong, MR. The Basal Ganglia IV: New Ideas and Data on Structure and Function. Percheron, G.; McKenzie, JS.; Feger, J., editors. Plenum Press; New York: 1994. p. 317-325.

153. Darvas M, Palmiter RD. Restriction of dopamine signaling to the dorsolateral striatum is sufficient for many cognitive behaviors. Proc. Natl Acad. Sci. USA. 2009; 106:14664-14669. [PubMed: 19667174]

154. Jubault T, Monetta L, Strafella AP, Lafontaine AL, Monchi O. L-dopa medication in Parkinson's disease restores activity in the motor cortico-striatal loop but does not modify the cognitive network. PLoS ONE. 2009; 4:e6154. [PubMed: 19584921]

155. Obeso JA, et al. What can man do without basal ganglia motor output? The effect of combined unilateral subthalamotomy and pallidotomy in a patient with Parkinson's disease. Exp. Neurol. 2009; 220:283-292. [PubMed: 19744484]

156. de Wit S, Barker RA, Dickinson AD, Cools R. Habitual versus goal-directed action control in Parkinson disease. J. Cogn. Neurosci. Apr 30.2010 (doi:10.1162/jocn.2010.21514).

157. Graybiel AM. Habits, rituals, and the evaluative brain. Annu. Rev. Neurosci. 2008; 31:359-387. [PubMed: 18558860] An excellent review of habitual behaviour.

158. DeLong M, Wichmann T. Changing views of basal ganglia circuits and circuit disorders. Clin. EEG Neurosci. 2010; 41:61-67. [PubMed: 20521487]

159. Draganski B, Bhatia KP. Brain structure in movement disorders: a neuroimaging perspective. Curr. Opin. Neurol. 2010; 23:413-419. [PubMed: 20610992]

160. Wilson SAK. Progressive lenticular degeneratio. A familial nervous disease associated with cirrhosis of the liver. Brain. 1912; 34:295-507.

161. Wilson SAK. Disorders of motility and tone. Lancet Neurol. 1925; 1:1-103.

162. Martin, J. Purdon Hemichorea resulting from a local lesion of the brain. (The syndrome of the body of Luys). Brain. 1927; 50:637-651.

163. Martin, J. Purdon; Alcock, NS. Hemichorea associated with a lesion of the corput Luysii. Brain. 1934; 57:504-516.

164. Denny-Brown, D. The Basal Ganglia. Oxford Univ. Press; Oxford: 1962.

165. Carpenter MB, Whittier JR, Mettler FA. Analysis of choreoid hyperkinesia in the Rhesus monkey; surgical and pharmacological analysis of hyperkinesia resulting from lesions in the subthalamic nucleus of Luys. J. Comp. Neurol. 1950; 92:293-331. [PubMed: 15422067] 
166. Martin JP, McCaul IR. Acute hemiballismus treated by ventrolateral thalamolysis. Brain. 1959; 82:104-108. [PubMed: 13651497]

167. Ehringer H, Hornykiewicz O. Distribution of noradrenaline and dopamine (3-hydroxytyramine) in the human brain and their behavior in diseases of the extrapyramidal system. Klin. Wochenschr. 1960; 38:1236-1239. [PubMed: 13726012]

168. Birkmayer W, Hornykiewicz O. The L-3,4-dioxyphenylalanine (DOPA)-effect in Parkinsonakinesia. Wien Klin. Wochenschr. 1961; 73:787-788. [PubMed: 13869404]

169. Cotzias GC, Papavasiliou PS, Gellene R. L-dopa in Parkinson's syndrome. N. Engl. J. Med. 1969; 281:272. [PubMed: 5791298]

170. Fahn S. The history of dopamine and levodopa in the treatment of Parkinson's disease. Mov. Disord. 2008; 23:S497-S508. [PubMed: 18781671]

171. Denny-Brown, D.; Yanagisawa, N. The Basal Ganglia. Yahr, MD., editor. Raven Press; New York: 1976. p. 145

172. Hassler R. Striatal control of locomotion, intentional actions and of integrating and perceptive activity. J. Neurol. Sci. 1978; 36:187-224. [PubMed: 206673]

173. Haber SN. The primate basal ganglia: parallel and integrative networks. J. Chem. Neuroanat. 2003; 26:317-330. [PubMed: 14729134]

174. Alexander, GE. Handbook of Brain Theory and Neural Networks. Arbib, MA., editor. MIT Press; Cambridge, Massachusetts: 1995. p. 139-144. 

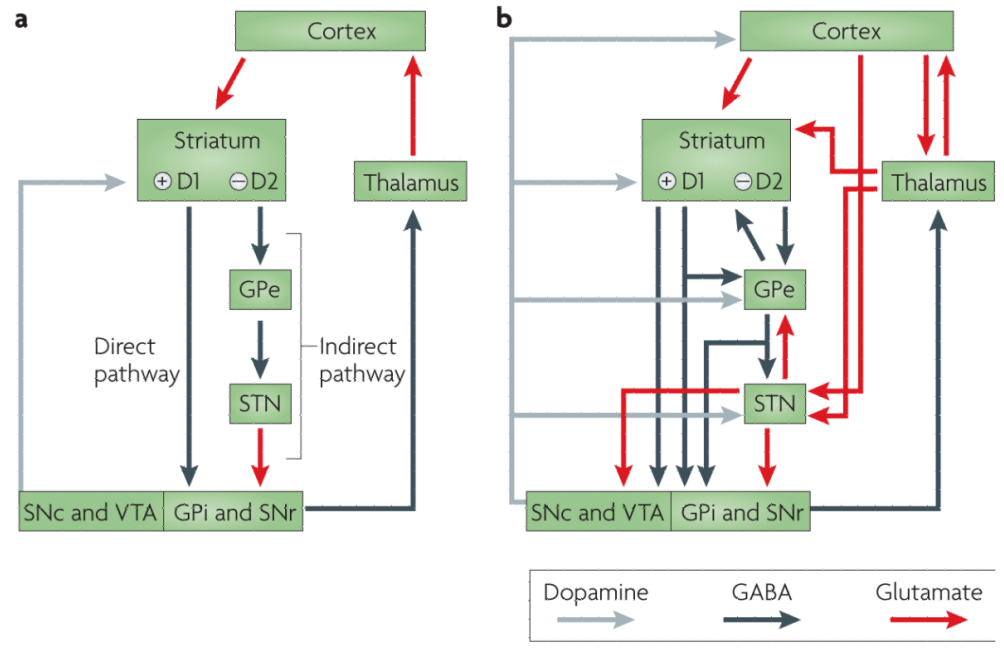

Figure 1. Organization of intrinsic connections within the basal ganglia

a I Model based on the influential proposal by Albin and colleagues ${ }^{3}$, according to which the output of the basal ganglia is determined by the balance between the direct pathway which involves direct striatonigral inhibitory connections that promote behaviour - and the indirect pathway - which involves relays in the external globus pallidus (GPe) and subthalamic nucleus (STN), and suppresses behaviour. The balance between these two projections was thought to be regulated by afferent dopaminergic signals from the substantia nigra pars compacta (SNc) and the ventral tegmental area (VTA) acting on differentially distributed D1 and D2 dopamine receptors. b I Recent anatomical investigations have revealed a rather more complex organization in which the transformations that are applied to the inputs to generate outputs are less easy to predict. GPe, globus pallidus pars externa; $\mathrm{GPi}$, globus pallidus pars interna; $\mathrm{SNr}$, substantia nigra pars reticulata. Figure is modified from REF. ${ }^{10} \odot$ P. Redgrave (2007). 
a

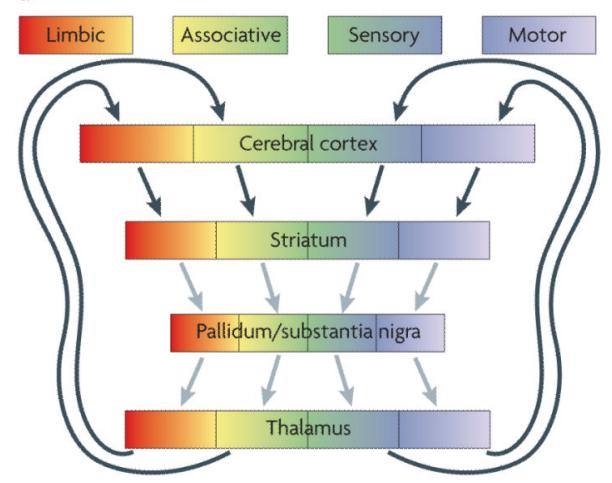

b

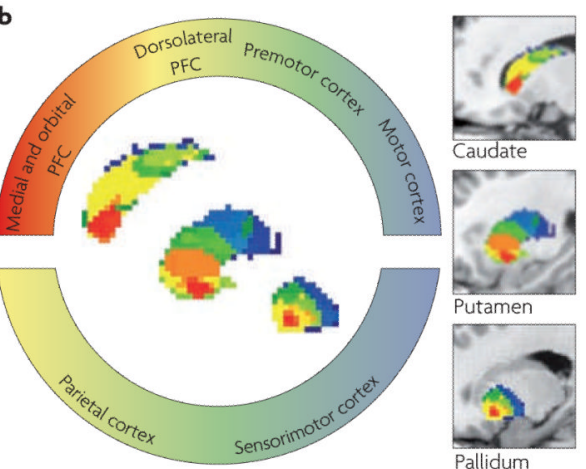

Figure 2. Corticobasal ganglia-cortical loops in animals and humans

a I The connections between the cerebral cortex and the basal ganglia can be viewed as a series of parallel-projecting, largely segregated loops or channels ${ }^{29}$ conveying limbic (shown in red), associative (shown in yellow-green) and sensorimotor (shown in bluewhite) information. Functional territories represented at the level of cerebral cortex are maintained throughout the basal ganglia nuclei and thalamic relays. Note, however, that for each loop the relay points in the cortex, basal ganglia and thalamus, offer opportunities for activity inside the loop to be modified or modulated by signals from outside the loop. Black arrows indicate glutamatergic projections, grey arrows indicate GABA $(\gamma$-aminobutyric acid)-ergic projections. b I The spatially segregated 'rostral caudal gradient' of human frontal cortical connectivity in caudate, putamen and pallidum. The colour-coded ring denotes limbic (shown in red), associative (shown in yellow-green) and sensorimotor regions of the cerebral cortex in the sagittal plane (colour coding after Haber ${ }^{173}$ ). Using probabilistic tractography on magnetic resonance-diffusion weighted imaging data, Draganski et al. identified the regions of the striatum that receive the strongest input from the identified cortical regions (sagittal oriented images contained within the ring) ${ }^{37}$. For better visualization, segmented basal ganglia nuclei are superimposed on T1-weighted structural images in the far right of the diagram (the rostral part is shown on the left, the caudal part is shown on the right). PFC, prefrontal cortex. Part a is modified, with permission, from REF. ${ }^{174}$ C (1995) MIT Press. Part b is reproduced, with permission, from REF. 37 (C) (2008) Society for Neuroscience. 

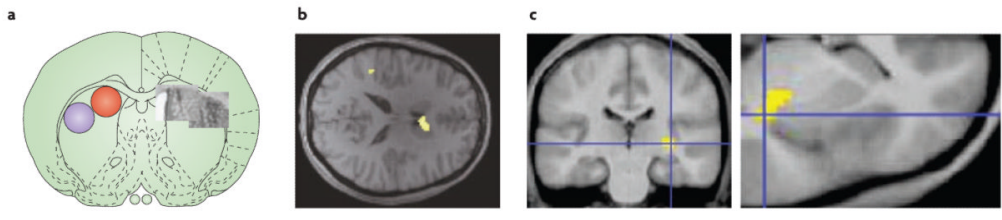

Figure 3. Striatal determinants of goal-directed and habitual action in rodents and humans a I Photomicrographs of NMDA ( $N$-methyl-D-aspartate)-induced cell-body lesions of the rat dorsomedial and dorsolateral striatum (shown in the right hemisphere) with approximate regions of lesion-induced damage illustrated with red and purple circles, respectively (shown in the left hemisphere). Lesions of the dorsomedial striatum abolished acquisition and retention of goal-directed learning ${ }^{85}$, whereas lesions of dorsolateral striatum abolished the acquisition of habit learning ${ }^{84}$. b I The regions of the human anterior dorsomedial striatum that exhibits sensitivity to instrumental contingency. $\mathbf{c}$ । The region of the human posterior lateral striatum (posterior putamen) that exhibits a response profile that is consistent with the development of habits in humans. Part a is reproduced, with permission, from REF. 65 (C) (2010) Macmillan Publishers Ltd. All rights reserved. Part b is reproduced, with permission, from REF. 95 C (2008) Society for Neuroscience. Part $\mathbf{c}$ is reproduced, with permission, from REF. 96 C (2009) Blackwell Publishing Ltd. 
a Control

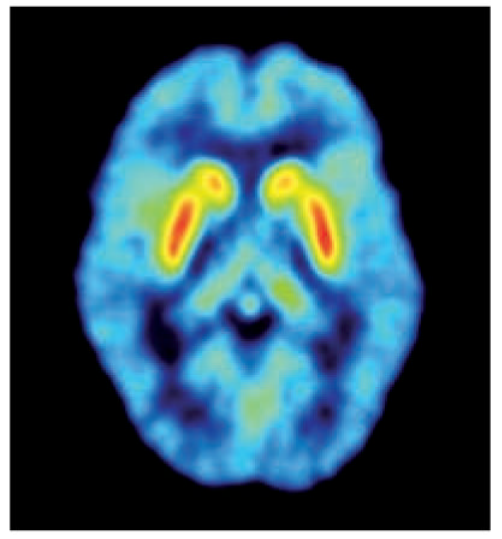

b Patient

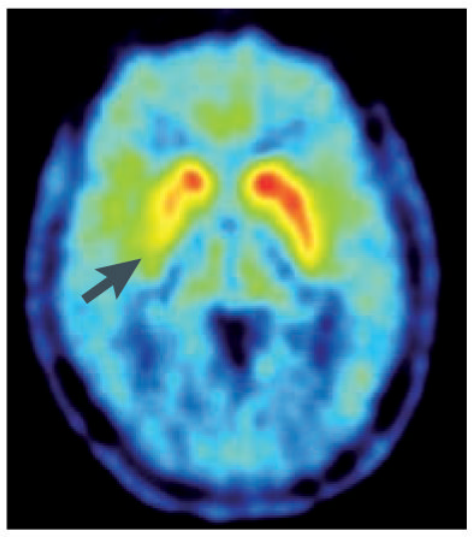

Figure 4. Striatal dopamine innervation assessed by ${ }^{18}$ fluorodopa positron emission tomography (PET)

a I PET scan from a control subject showing high uptake of ${ }^{18}$ fluorodopa in the striatum (highest uptake values are shown in white). b I An example of a PET scan from a patient with Parkinson's disease with motor signs that are mainly confined to the right limbs. ${ }^{18}$ Fluorodopa uptake is markedly reduced in the left posterior putamen (the uptake in the area indicated by the arrow is $70 \%$ below normal) and reduced to a minor extent in the anterior putamen and caudate of the left hemisphere. 


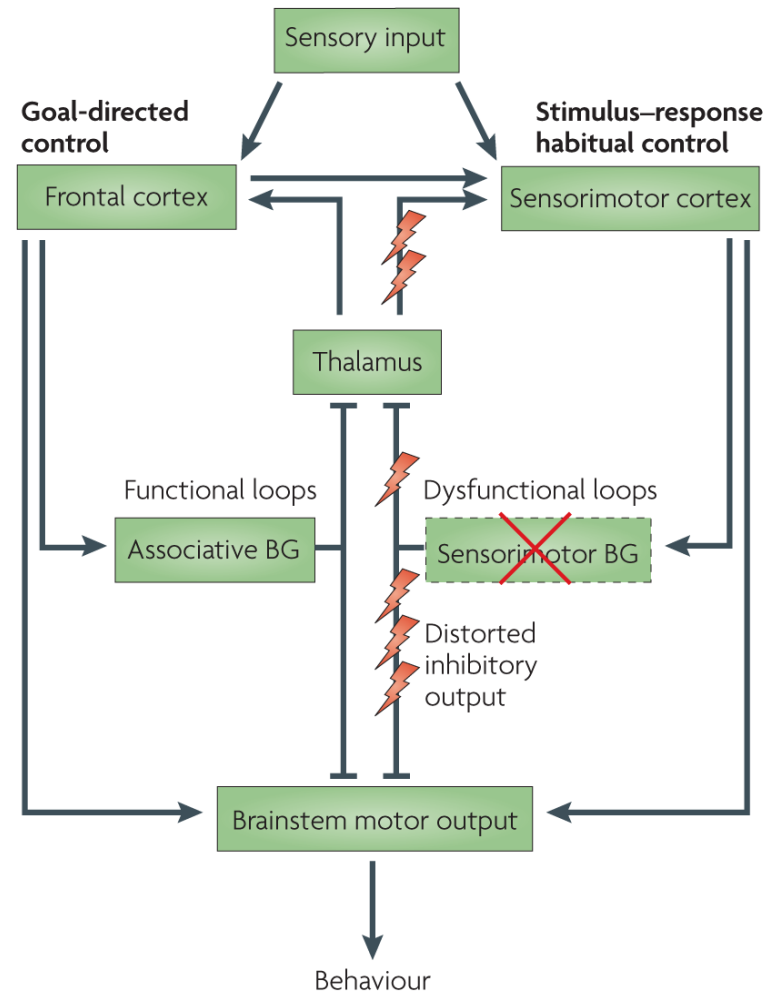

Figure 5. Functional and dysfunctional loops through the basal ganglia in the parkinsonian state Both goal-directed and habitual control systems receive sensory inputs. Goal-directed control is dependent on the associative networks through the basal ganglia, whereas stimulus-response habitual control relies on the sensorimotor territories. Both networks independently have the capacity to direct behavioural output via 'final common motor pathways' (REFS ${ }^{84},{ }^{85},{ }^{87}$ ). There may be many sites at which output from the two control systems might converge, and two have been illustrated: one at the level of cortical motor output, the other in the brainstem. In Parkinson's disease, differential loss of dopamine innervation from sensorimotor regions in the basal ganglia (shown by the red cross) causes dysfunctional output signals from these territories and their associated networks (shown by lightning symbols). Presumably, this loss of function causes an increased reliance on goaldirected control. In addition, the distorting inhibitory output from sensorimotor territories is likely to impede the execution of goal-directed behavioural control that is otherwise comparatively preserved. BG, basal ganglia. 